\title{
Thermal diagnostic of power transistor at increased junction temperatures
}

\author{
by Z. Radivojević, K. Andersson, R.Lehtiniemi, J. Rantala
}

Nokia Research Center, P.O. Box 407, FIN-00045 NOKIA GROUP, Finland.

e-mail: zoran.radivojevic@nokia.com

\begin{abstract}
Infrared (IR) thermography in power-cycling experiments was combined in reliability studies of an RF power amplifier, operating at elevated junction temperatures. A powercycling technique (adjusted to reach high junction temperatures) was used as a life acceleration method. Several sets of IR measurements were performed for various working conditions to correlate the device power and the maximum junction temperatures. Finite element (FE) simulations in combination with traditional failure analysis methods were employed to examine main failure causes. IR thermography was used for experimental validation of temperature distributions obtained by the simulations. Furthermore, the validated FE model has been extended to achieve stress distribution and reliability predictions via selection of the most risky areas. The entire procedure can provide reliable, evaluated information of the governing thermal resistances and enable optimizing the required cooling arrangement.
\end{abstract}

\section{Introduction}

Flange mounted RF Power Amplifier (RF-PA) transistors usually operate under severe conditions. This often increases collector dissipation and consequently junction temperature $(T j)$. Failure mechanisms in high power transistors are highly temperature dependent, so proper attention must be paid to their thermal management. The example studied here belongs to the RF-PA family being used in professional mobile radio communications like military or police base-stations. Both numerical simulations and dedicated experimental tests are performed to obtain knowledge about functional capacity of the component.

Understanding of performances at the edge of operating window is examined by power-cycling experiments that introduce severe working conditions. Usually the designers' practice is using the device in a narrower environmental and operating window than its manufacturer designed limits. The simplest approach deals with limiting maximum junction temperature, power or voltages for example to $60 \%$ of manufacturer rated limits.

However, today's failure root-cause does not depend only on steady-state temperature but on thermal mismatches due to environmental or power-cycling. This involves the complexity of transient temperature behaviour of the whole assembly. In this work, simulations and experiments are combined to obtain information about the safety margins and risks when operating at higher power. FE-simulations were used to calculate the temperature and stress field in the component.

\section{Experimental testing}

Experiments involved in testing of the RF-PA [1] were designed to validate simulations and perform life acceleration of the component in accordance with expected failures as in the real field conditions. To have reasonable time of the testing, it was necessary to introduce severe working conditions. Particularly it deserved fast heating-up and efficient cooling-down conditions for the component introducing severe but controlled thermal transients and gradients. The practical arrangement involved a set of the RF-PA stimulated in the DC mode allowing for drain-source currents $\left(I_{d s}\right)$ of up to 5-7 A. Several 
sets with the components were used and each set was adjusted to reach different $T j$ in the peak of a single power cycle. Each set consisted of two RF-PA assembled on a printed wiring board (PWB) as presented in Fig 1a. One component per set was decapped to have direct access to the die-surface for the IR measurements.

The I/O contacts of the component were soldered to the PWB to provide biasing and stimulation and connect the signals to the data acquisition system. The flanges of the component were attached to a 4-pass water cooled heat sink (6063-T5 Aluminium type from AAVID Thermalloy [2]) to allow for fast and efficient cooling. The water had a temperature of $10^{\circ} \mathrm{C}$, its flow rate was $4 \mathrm{l} / \mathrm{min}$. Five test sets were mounted on the heat sink. Special attention was paid to have a well determined pressure in the coupling bolts when tightening the coupling mechanism. Several thermocouples were mounted into the heat sink to monitor temperatures inside (Fig 1b).

The power cycle consisted of $5 \mathrm{~min}$ for ramp-up and $2 \mathrm{~min}$ for ramp-down. For each of the five PWBs, the biasing and stimulation were adjusted in such a way that the maximum junction temperatures $\left(T_{\text {jmax }}\right)$ of the test sets reached $180^{\circ} \mathrm{C}, 190^{\circ} \mathrm{C}, 200^{\circ} \mathrm{C}, 220^{\circ} \mathrm{C}$, and $240^{\circ} \mathrm{C}$, respectively. At the end of the ramp-down, the temperature of the heat sink was the same as of the running water $\left(10^{\circ} \mathrm{C}\right)$. On-line monitoring of the component parameters and failures was provided by recording biasing voltages $\left(V_{b}\right)$ and drain currents $\left(I_{d s}\right)$ as function of number of cycles. Dramatic changes of these parameters $\left(V_{b}\right.$, $I_{d s}$ ) indicate that some failures had occured.

During the power cycle, the surface temperature of black-painted dies to level and increase the emissivity value was observed with an IR camera which contained a FLIR SC3000 Quantum Well IR Photodetector (QWIP) operating at 8-9 m wavelength. Three different lenses were used: standard optics $\left(20^{\circ} \times 15^{\circ}, 1.1 \mathrm{mrad}\right.$ IFOV), a close-up lens with $34 \mathrm{~mm} \times 26 \mathrm{~mm}$ and one with $10 \mathrm{~mm} \times 7.5 \mathrm{~mm}$ imaging areas. The thermal sensitivity of the camera at room temperature is better than $20 \mathrm{mK}$ and its measurement accuracy better than $\pm 1 \%$ or $\pm 1^{\circ} \mathrm{C}$, whichever is larger. The camera can record $320 \times 240$ pixel live thermal images at a frame rate of $50 \mathrm{~Hz}$.

\section{Modeling and simulations}

A parameterised FE-model for the RF-PA component was constructed in the ANSYS APDL language. The FE-simulations were performed by using a sequential coupled-field analysis approach. In the first step the thermal field is calculated in the component. In the second step the thermal field is used as a load in the stress calculations. In both FEanalyses a linear model is used. The heat sink is not included in the stress calculations but it is taken into account by constraining the movement of the flange near the screws, which couples the flange to the heat sink (see Fig 1b). To reduce the amount of simulations, a mathematical model was constructed for calculating the maximum temperature and stress in different locations of the component. The mathematical model was constructed by running $27 \mathrm{FE}$-simulations and using the design of the experimental technique [3]. The model takes into account the effect of the temperature in the water channel, the power applied to the component and the heat conduction between flange and heat sink.

\section{Discussion and results}

To investigate the thermal and reliability properties of the RF-PA component at elevated junction temperatures, a stress analysis has been performed by using ANSYS software. Thermal modelling was performed and compared to the results of IR measurements. Fig. 3 presents IR images taken on the decapped component mounted on the heat sink for several biasing and power dissipation levels $\left(P_{\text {diss }}\right)$. The temperature distribution for $P_{\text {diss }}=173 \mathrm{~W}$ was used to validate the thermal model and to implement it. Notice that this power level still keeps $T j$ below $200^{\circ} \mathrm{C}$. The results of the stress simulations presented in Fig. 4 are for the most sensitive parts of the package. 
The constructed thermo-mechanical model involved bolts and a pressure coupling mechanism parameterised and implemented into the simulations. The areas close and under the bolts are more effective for the heat transfer. Notice that the right corner of the right die at Fig $4 a$ is cooled more effectively. Fig $4 \mathrm{~b}$ confirms that the applied power on the silicon die $(173 \mathrm{~W})$ is still in the safe range. The maximum stress level $\left(S_{\max }=47 \mathrm{MPa}\right)$ is still below the critical value. The material properties were obtained by using the MatWeb data-base and the Cindas software [4].

Fig 5a shows the yield strength for two materials involved in the component construction. Figures 4c,d present temperature and stress distribution for the solder. Both figures confirm that the applied power level is still within safe limits $\left(S_{\max }=143 \mathrm{MPa}\right)$. The melting temperature of the solder is $363^{\circ} \mathrm{C}$ and cracking strength is at $200 \mathrm{MPa}$. Figures $4 \mathrm{e}, \mathrm{f}$ show the location of the risky areas in the ceramic cap. Notice that the hottest place is between the two dies, however, the most critical area is just at the cap middle. Figures 6 $a, b$ present simulation results for the component flange. As expected the hottest points are close to the die $\left(T_{\max }=144^{\circ} \mathrm{C}\right)$. However, the stress maximum is just between the two dies. Fig 6c shows results for the out-of-plane movement of the flange. In the case of $P_{\text {diss }}=173 \mathrm{~W}$ the maximum value obtained for the displacement at the flange center is 3.5 $\mu \mathrm{m}$.

Furthermore, a parametric study has been performed by changing the level of power dissipation (and $T_{\text {jmax }}$ ) to obtain information about the flange bending. Fig $5 \mathrm{~b}$ shows the results of maximal displacement as function of $T_{j \max }$. In the calculation the bolt pressure was set to $F_{B}=0.6 \mathrm{Nm}$ as an optimum value. It was noticed that the central area of the flange contributes much less to the heat transfer than previously assumed and that tightening with higher $F_{B}$ does not improve significantly the thermal conductivity between the flange and the heat sink.

\section{Conclusions}

This work presents a study performed by using experimental and numerical methods to examine the thermo-mechanical reliability of the RF power-amplifier at elevated junction temperatures. If the applied power is about $173 \mathrm{~W}$ and maximum junction temperature is kept below $T_{\text {jmax }} \leq 200^{\circ} \mathrm{C}$, the resulting stress level is still within safe operating margins. This is valid for coupling conditions of $0.6 \mathrm{Nm}$ for tightening of the bolts. In these conditions the flange bending does not cause excessive deformation $(3.5 \mu \mathrm{m})$ of the underside of the flange. At higher torques the thermal contact resistance is possibly not improved due to potential bending of the flange. However, an advanced solution might be to use an interface material to increase the flexibility in the out-of-plane direction. This is very important if the component is used at elevated temperatures $\left(T_{\text {jmax }} \geq 200^{\circ} \mathrm{C}\right)$.

If exceeding these margins, an advanced cooling technique might be considered such as using efficient heat-spreaders in combination with soft interface materials for both elastic and good thermal coupling between the component flange and the heat sink. Furthermore, in the packaging architecture an advanced ceramic cap might be considered which will account for the highest stress located at the middle of the ceramic cap.

\section{REFERENCES}

[1] Philips Research Laboratories, Eindhoven The Netherlands.

[2] AAVID Thermalloy, Power Devices Inc., 26941 Cabot Road 124, Laguna Hills, CA 92653.

[3] Design of Experiments Principles and Applications, L.Eriksson et al. , Umetrics AB Box 7960 SE90719 Umeå, Sweden.

[4] CINDAS material database, version 2.11, 1999. 


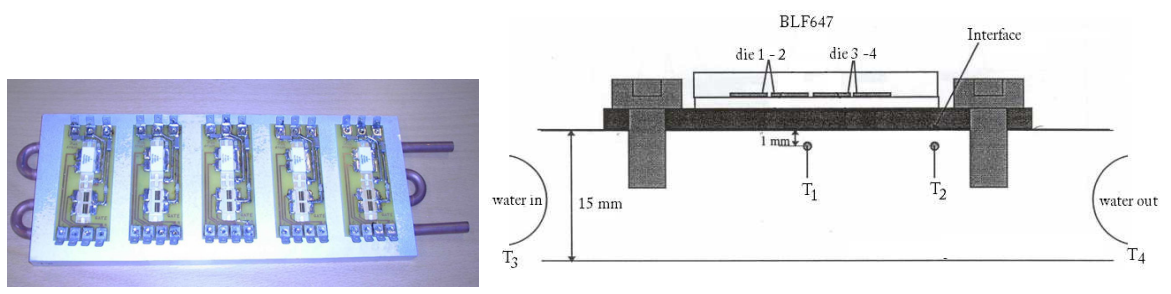

Fig. 1. Left: Experimental set-up for power-cycling experiment with RF-PA. Right: Cross-section scheme of the RF-PA component mounted on the on water-cooled heat sink. Notice position of the thermocouples
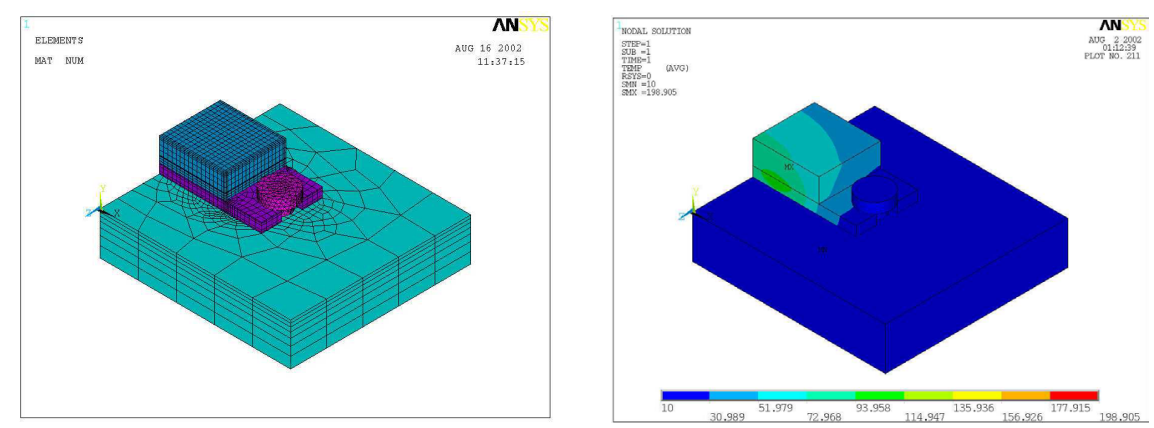

Fig. 2. $1 / 2$ symmetry FE model developed by using ANSYS software. Left: Model grid. Right: Corresponding temperature distribution of the whole assembly
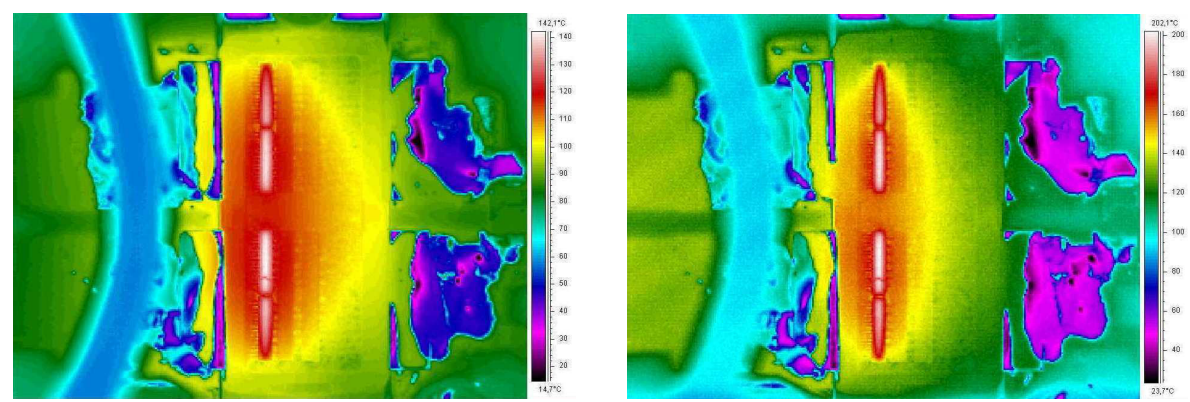

Fig. 3. IR pictures taken on the decapped RF-PA for two different biasing $\left(V_{b}, l_{d}\right)$ conditions. Left: The biasing No 1. $\left(\mathrm{V}_{\mathrm{b}}=5.3 \mathrm{~V} ; I_{d}=1.7 \mathrm{~A}, \mathrm{P}_{\mathrm{diss}}=88 \mathrm{~W}\right)$. Right: Biasing No $2\left(\mathrm{~V}_{\mathrm{b}}=5.7 \mathrm{~V} ; \mathrm{I}_{\mathrm{d}}=5 \mathrm{~A}, \mathrm{P}_{\text {diss }}=173 \mathrm{~W}\right)$ 
http://dx.doi.org/10.21611/qirt.2002.023

a)

b)
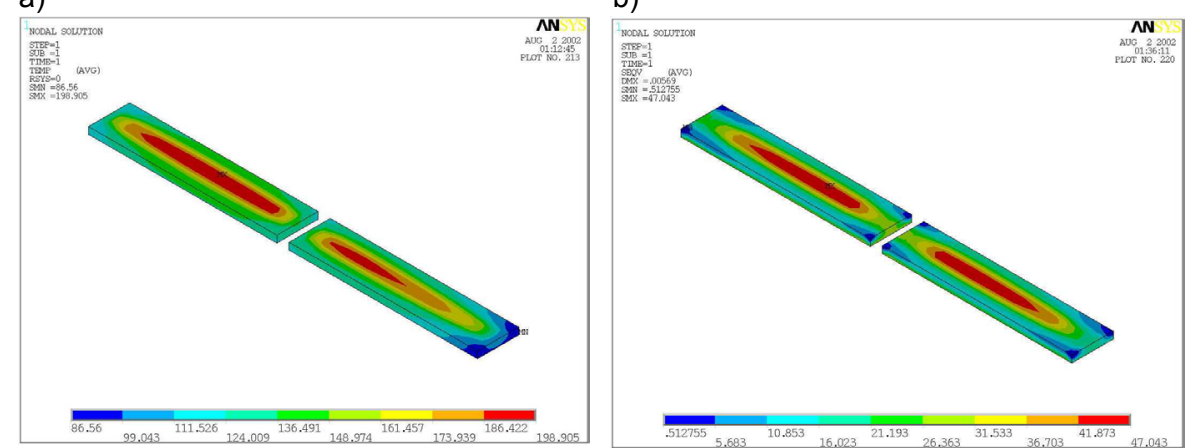

c)

d)
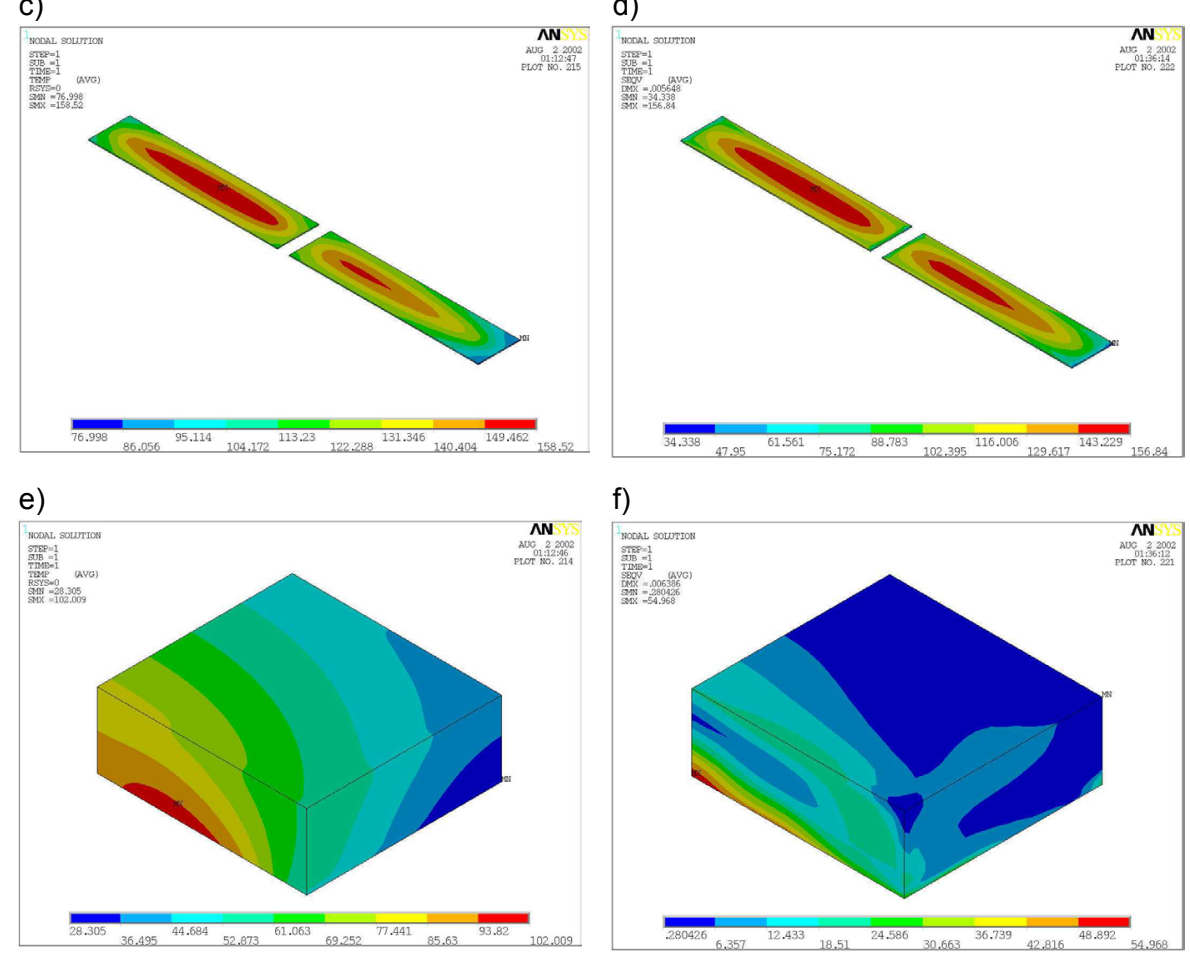

Fig. 4. ANSYS simulation results for temperature and stress distribution for $\mathrm{P}_{\text {diss }}=173 \mathrm{~W}$.

$a, b)$ silicon die $\left(T_{\max }=199, \mathrm{~S}_{\max }=47 \mathrm{MPa}\right)$;

$c, d)$ solder $\left(T_{\max }=158, \mathrm{~S}_{\max }=157 \mathrm{MPa}\right)$;

e,f) ceramic cap $\left(T_{\max }=102, S_{\max }=55 \mathrm{MPa}\right)$ 

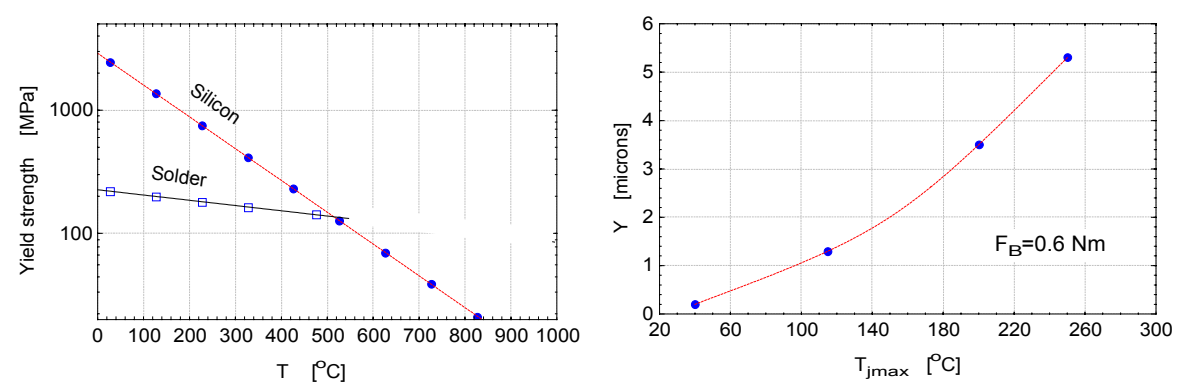

Fig. 5. Left: Yield strength for materials involved in the RF-PA construction. Right: Outof-plane deflection of the flange at the center of the component as a function of $\mathrm{T}_{j \max }$

a)

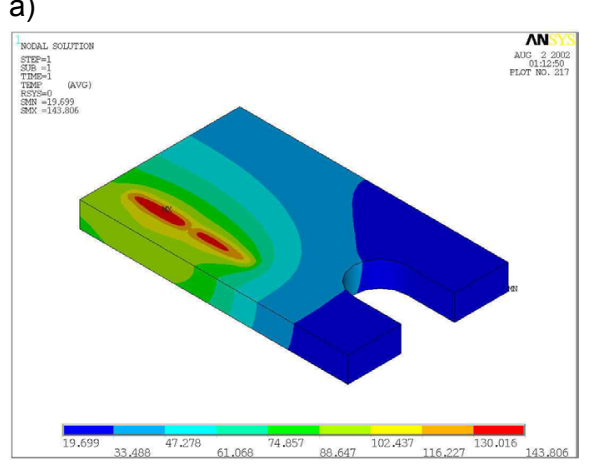

b)

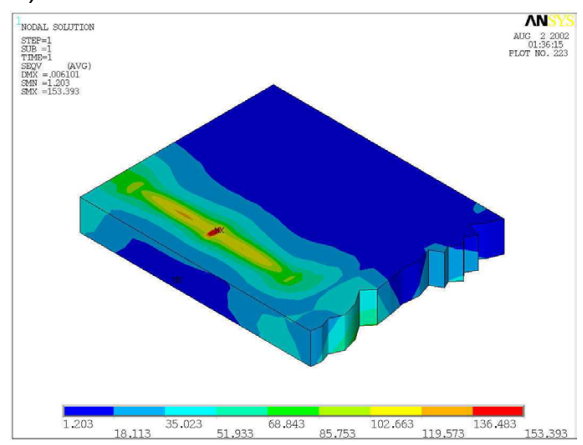

c)

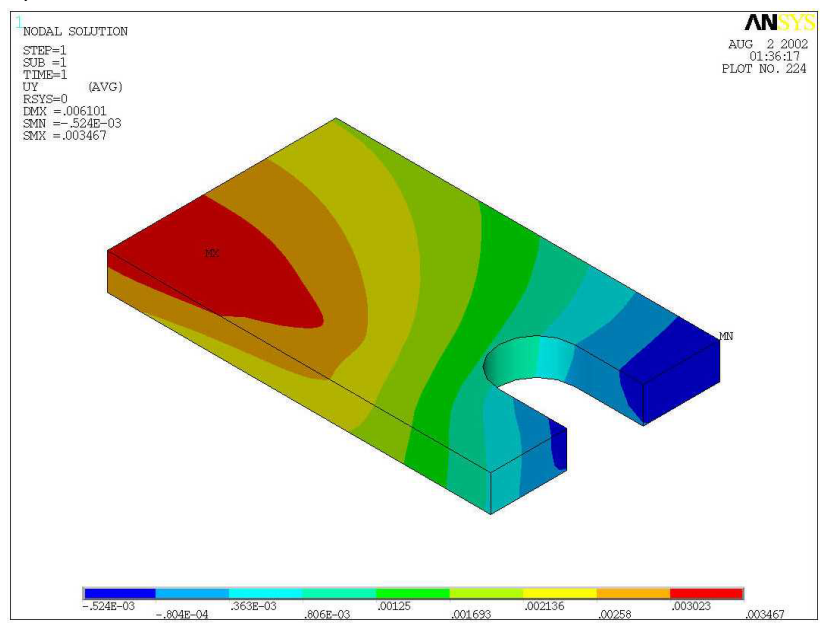

Fig. 6. ANSYS simulation results for $\mathrm{P}_{\text {diss }}=173 \mathrm{~W}$.

a,b) Temperature and stress distribution at the component flange $\left(T_{\max }=144^{\circ} \mathrm{C}, S_{\max }=153 \mathrm{MPa}\right)$.

c) Corresponding out-of-plane movement of the flange 